\title{
Adjuvant Chemotherapy is Associated with Improved Survival After Esophagectomy without Induction Therapy for Node- positive Adenocarcinoma
}

\author{
Paul J Speicher, MD, Brian R Englum, MD, Asvin M Ganapathi, MD, Michael S Mulvihill, \\ MD, Matthew G Hartwig, MD, Mark W Onaitis, MD, Thomas A D'Amico, MD, and Mark F \\ Berry, MD \\ Department of Surgery, Duke University Medical Center, Durham, North Carolina, United States
}

\begin{abstract}
Background-This study investigated adjuvant chemotherapy(AC) use after esophagectomy without induction therapy for node-positive ( $\mathrm{pN}+$ ) adenocarcinoma using the National Cancer Database (NCDB), including the impact of complications related to surgery (CRS) on outcomes.

Methods-Predictors of AC use in 1,694 patients in the NCDB who underwent R0 esophagectomy from 2003-2011 without induction therapy for $\mathrm{pN}+$ adenocarcinoma of the middle or lower esophagus and survived $>30$ days were identified with multivariable logistic regression. The impact of AC on survival was estimated using Kaplan-Meier and Cox-proportional hazards methods.
\end{abstract}

Results-AC was given to 874/1,694 (51.6\%) patients; 618 (70.7\%) AC patients received radiation. Older age (AOR 0.58/decade, $\mathrm{p}<.001$ ), longer travel distance (AOR 0.78/100 miles, $\mathrm{p}=$. 03) and CRS (AOR 0.45, $\mathrm{p}<.001$ ) predicted that $\mathrm{AC}$ was not used. Patients given AC had better 5 year survival than patients not given $\mathrm{AC}(24.2 \%$ vs $14.9 \%, \mathrm{p}<.001)$, and $\mathrm{AC}$ use predicted improved survival in multivariate analysis (HR $0.67, \mathrm{p}=0.008$, Table). Receiving radiation in addition to AC did not improve survival ( $\mathrm{p}=0.35$ ). Although CRS was associated with worse survival, patients who had CRS but received AC had superior survival compared to patients who did not have CRS or get $\mathrm{AC}(\mathrm{p}=.016)$.

Conclusions-AC following esophagectomy is associated with improved survival but was only used in half of patients with $\mathrm{pN}+$ esophageal adenocarcinoma. We also found that the addition of radiation to $\mathrm{AC}$ was not associated with a survival benefit. CRS predict worse long-term survival and lower the chance of getting AC, but even patients with CRS had improved survival when given AC.

\section{Keywords}

esophageal cancer; adjuvant chemotherapy; post-operative complications

Correspondence: Dr. Mark F. Berry, Box 3652, Duke University Medical Center, Durham, NC 27710, Phone: 919-613-4696 | Fax: 919-684-8508, berry037@mc.duke.edu.

Meeting: Presented in part at the 50th annual meeting of the American Society of Clinical Oncology. Chicago, Illinois. May 30-June 3, 2014. 


\section{Introduction}

Approximately 57\% of all esophageal cancers in the United States are adenocarcinomas, with an increasing incidence in recent years.[1-6] Esophageal adenocarcinomas are found in the distal esophagus in three quarters of cases.[2] Overall approximately $32 \%$ of esophageal cancer patients have regional disease at the time of diagnosis.[1,2,7] The treatment for locally advanced esophageal cancer that does not have distant metastases and is potentially resectable (T3-4aN0, T1-4aN1M0) is highly variable in practice.[8] However, recent evidence suggests that induction chemoradiation followed by surgical resection is the optimal treatment for patients with nodal disease (pN+).[9-15] For patients with $\mathrm{pN}+$ adenocarcinoma who are treated primarily with surgical resection, the National Comprehensive Cancer Network (NCCN) guidelines recommend adjuvant chemoradiation. [16]

However, the use of adjuvant therapy after esophagectomy for adenocarcinoma has not been well characterized. Recommendations related to adjuvant therapy for esophageal adenocarcinoma are derived from trials that exclusively or predominantly included patients with gastric carcinoma.[17-23] One potential difficulty with translating results from those studies is that a patient's ability to tolerate adjuvant treatment may differ between gastrectomyand esophagectomy. Esophagectomy is associated with significant morbidity despite improvements over time, and complications can more than double already long hospital stays and overall recovery periods.[24-31] Both patients and their providers may be reluctant to consider potential risks associated with adjuvant therapy after esophagectomy, especially if the patient had a difficult perioperative course. Currently the paucity of data regarding the use of adjuvant therapy limits clinicians' ability to appropriately counsel patients on the risks and benefits. This study was undertaken to examine the role of adjuvant therapy following surgical resection for adenocarcinoma of the esophagus using a large national clinical database and attempt to improve the available level of evidence, particularly with regard to the potential benefits of adjuvant oncologic therapy in patients with postoperative complications.

\section{Methods}

This retrospective analysis of patients in the National Cancer Data Base (NCDB) undergoing esophagectomy for esophageal cancer from 2003-2011 was approved by the Duke University Institutional Review Board. The NCDB currently contains over 30 million records by collecting data from more than 1,500 CoC-approved facilities across the United States, and is estimated to capture approximately $70 \%$ of all newly diagnosed U.S. cases of cancer annually. Patients with adenocarcinoma of the mid- and distal third of the esophagus were identified using International Classification of Diseases for Oncology, $3^{\text {rd }}$ Edition (ICD-O-3) topography and histology codes. Pathologic TNM staging data was directly extracted using the American Joint Commission on Cancer (AJCC) $6^{\text {th }}$ and $7^{\text {th }}$ edition staging manuals depending on year of diagnosis, and only patients with $\mathrm{N}+$ disease were kept for analysis. As our primary predictor variable was the use of adjuvant chemotherapy (AC) following oncologic resection, only patients with negative (R0) margins who survived at least 30 days postoperatively were included. Patients who received induction therapy of 
any kind were excluded, as were patients with missing data regarding the specific timing of chemoradiation therapies.

Patients were stratified into two groups based on the use of AC versus postoperative observation. Baseline patient characteristics and postoperative outcomes were compared using the Mann Whitney U test for continuous variables and Pearson's chi-square test for discrete variables. Trends over time were examined with the Cochran-Armitage trend test. Since the NCDB does not contain data regarding specific perioperative morbidity, we defined postoperative complications as cases that involved either an unplanned readmission, or a length of stay of at least 20 days following esophagectomy. Predictors of AC were identified using multivariable logistic regression modeling, which included age, sex, race, Charlson/Deyo comorbidity score, median census tract education and income levels, TNM pathologic T-stage, patient distance from treatment facility, and presence of a postoperative complication as defined above.

The Kaplan-Meier method was used to estimate overall survival, which was defined as time from diagnosis to death or censor. Cancer-specific survival is not available in the NCDB. To estimate the independent effect of AC on survival, a Cox proportional hazards model was developed that included age, sex, race, comorbidity burden, pathologic $\mathrm{T}$ stage, and treatment facility volume. To examine whether postoperative complications were confounding any potential differences between the treatment groups, we conducted a subgroup analysis of assessing long-term survival only for those patients who did not experience a complicated course. Likewise, we explored survival among patients who received $\mathrm{AC}$, stratified by the presence of postoperative complications, focusing on how rescue from such complications affects survival for patients who received AC, compared to patients receiving $\mathrm{AC}$ in the setting of no major complications.

We made an affirmative decision to control for type I error at the level of each comparison. A p-value $<0.05$ was considered statistically significant for all comparisons. Missing data was handled with complete case analysis given the substantial completeness of the NCDB for the study population investigated. All statistical analyses were performed using $\mathrm{R}$ version 3.0.2 (R Foundation for Statistical Computing, Vienna, Austria).

\section{Results}

Of 1,694 node-positive patients in the NCDB who did not receive induction therapy and survived at least 30 days after surgery, $874(51.6 \%)$ were treated with AC, and 618 of these (70.7\%) also received radiation therapy post-operatively. Use of chemotherapy significantly increased over time, from $45 \%$ of patients in 2003 to $57 \%$ in 2011, p<0.001 (Figure 1). Baseline unadjusted characteristics are shown in Table 1, with the patients who received adjuvant therapy being younger, with lower comorbidity burden, were more likely to have private insurance, and had significantly shorter hospital length of stays following esophagectomy. Following multivariable adjustment, older age (adjusted odds ratio [AOR] 0.58 /decade, $\mathrm{p}<.001$ ), longer travel distance (AOR 0.78/100 miles, $\mathrm{p}=.03$ ) and presence of postoperative complications (AOR 0.45, $\mathrm{p}<.001$ ) predicted that AC was not used (Table 2). A total of 1,470 (86.8\%) patients had complete data regarding unplanned readmission and 
hospital length of stay. Of patients not experiencing post-operative complications, 587 (54.4\%) were treated with AC, while among patients who experienced a complication, only $130(33.3 \%)$ went on to received AC.

Median survival for patients given AC was 24.8 months versus 16.7 months for patients treated with surgery alone ( $\mathrm{p}<.001$, Figure 2A). Patients given AC had better 5-year survival than patients not given AC (24.2\% versus 14.9\%), and AC use predicted improved survival in multivariable analysis (hazard ratio [HR] 0.67, $\mathrm{p}=0.008$, Table 3 ). Although postoperative complications were associated with worse survival (HR $1.5, \mathrm{p}=0.01$ ), adjuvant therapy use was still associated with a significant survival advantage after excluding all patients who experienced a postoperative complication (5-year survival: $24.7 \%$ versus $16.0 \%, \mathrm{p}<.001$; Figure 2B). More importantly, patients who experienced postoperative complications and were subsequently rescued to receive intended $\mathrm{AC}$ had similar survival compared to patients who received $\mathrm{AC}$ in the absence of complications ( $\mathrm{p}=0.78$, Figure $3 \mathrm{~A}$ ), but had superior survival compared to patients who did not experience complications but also did not get AC $(p=.016$, Figure 3B). In an exploratory analysis examining the effect of adding adjuvant radiation therapy to $\mathrm{AC}$, no significant improvement in survival was found between patients who were given $\mathrm{AC}$ and radiation compared to patients who were only given $\mathrm{AC}(\mathrm{p}=0.35)$.

\section{Discussion}

In this study, we found that the use of AC following esophagectomy is associated with significantly improved survival for patients for $\mathrm{pN}+$ esophageal adenocarcinoma not treated with induction therapy. Despite increasing rates of AC use over time, we found that only approximately half of patients treated with esophagectomy without induction therapy for $\mathrm{pN}$ + esophageal adenocarcinoma in the NCDB ultimately received AC treatment postoperatively. While complications related to surgery both significantly lower the probability of treatment with $\mathrm{AC}$ and predict worse long-term survival overall, patients who adequately recover from complications and subsequently receive $\mathrm{AC}$ do derive benefits with respect to long-term survival.

The use of adjuvant therapy after esophagectomy for adenocarcinoma is poorly characterized. Recommendations related to adjuvant therapy for esophageal adenocarcinoma are derived from trials that exclusively or predominantly included patients with gastric carcinoma.[17-23] The NCCN recommendations for adjuvant chemoradiation therapy after esophagectomy are primarily based on the Intergroup-0116 study. In this study of 556 patients with adenocarcinoma of the stomach or cardia, $85 \%$ of whom had pathologic nodal disease, patients given adjuvant chemoradiation (45 Gy combined with 5-FU and leucovorin) had significantly better three year survival compared to patients treated with surgery alone (50\% versus $41 \%$, hazard ratio $1.32, \mathrm{p}=0.0046)$. $[17,18]$ However, only $20 \%$ of these patients had cancer in the proximal stomach or gastroesophageal (GE) junction area. Similarly, the ARTIST trial compared adjuvant chemoradiation ( 2 cycles cisplatin and capecitabine then 46 Gy with capecitabine for 5 weeks and then 2 more cycles of cisplatin and capecitabine) and chemotherapy alone ( 6 cycles of cisplatin and capecitabine) in 458 patients with adenocarcinona of the stomach or GE junction, and found chemoradiation was associated with improved disease-free survival in the subgroup of patients who had 
pathologic lymph node metastases at the time of surgery, but overall no difference in 3 year disease-free survival.[19] Pathological nodal disease was present in $86 \%$ of the patients, but only $5 \%$ of patients had GE junction tumors. Similarly, studies of adjuvant chemotherapy have also included very limited numbers of esophageal cancer patients. The Asian Phase III Adjuvant Chemotherapy Trial of S-1 for Gastric Cancer (ACTS-GC) was a study of 1059 Japanese patients with gastric adenocarcinoma, most of whom were stage II or III, that found adjuvant chemotherapy (one year of the oral fluoropyrimidineS-1) was associated with better survival than surgery alone $(71.7 \%$ versus $61.1 \%$, hazard ratio 0.669$) .[20,21]$ However, this study only included patients with stomach cancer and involved a drug that is not widely used outside of Asia. The CLASSIC study did include patients with GE junction adenocarcinomas and found patients that were given adjuvant chemotherapy ( 8 cycles capecitabine and oxaliplatin) had better overall five year survival compared to patients treated with surgery alone (78\% vesus 69\%, $\mathrm{p}=0.0029)$. [22, 23] This Asian trial of 1035 patients included $90 \%$ who had nodal disease, but $98 \%$ of included patients had gastric cancer with only the remaining $2 \%$ having GE junction cancers.

Using data related to gastric adenocarcinoma to guide treatment of esophageal adenocarcinoma does have some validity. Adenocarcinoma of the GE junction (GEJ) is treated and staged similarly to more proximal esophageal cancers of the proximal esophagus, but is considered to be significantly less radiosensitive than other esophageal cancers and is biologically more closely related to gastric adenocarcinoma.[32] However, surgical resection and subsequent reconstruction of gastrointestinal continuity for esophageal cancer is more complex than that for gastric cancer, which can impact the ability to tolerate additional therapy postoperatively and therefore limit the ability to extrapolate gastric adenocarcinoma treatment data to patients with esophageal cancer. Our current study quantifies the impact of postoperative complications on outcomes and the use of adjuvant chemotherapy among patients with esophageal cancer. Although the NCDB does not have specific data available regarding postoperative morbidity, our definition based on unplanned readmission within 30 days or a length of stay of three weeks or greater captures patients who did not have a completely uneventful postoperative course. Importantly, our study shows that patients who have postoperative complications but still receive AC have survival that is similar to that of those patients who have an uncomplicated course and are treated with $\mathrm{AC}$ as planned, and is markedly better than for patients who do not experience a complication but are also not treated with AC. This data can guide patient counseling, as patients reluctant to consider additional therapy may be more amenable if the potential benefits of improved survival are better quantified.

Recent evidence suggests that induction chemoradiation followed by surgical resection is the optimal treatment for patients with locally advanced but resectable esophageal cancer.[9-15] There are several potential reasons why patients in this current study may not have been given induction therapy. First, the patients may have been treated at institutions where induction therapy was not routinely considered. Second, induction therapy may been considered inappropriate do to specific patient characteristics, such as medical comorbidities or previous chemotherapy or radiation therapy. Third, the patients may have been understaged pre-therapy due to limitations of current staging modalities.[33-38] Our study does suggest that adjuvant therapy likely provides benefit to patients who are primarily 
treated with surgery due to initial understaging. However, clinicians may want to more strongly consider induction therapy prior to esophagectomy whenever there is suggestion of nodal or more advanced disease, considering our finding that only about half of patients get $\mathrm{AC}$ and therefore all of the recommended treatment when nodal disease is discovered after primary therapy with esophagectomy.

Younger age and the absence of a complicated postoperative course were both strongly associated with the use of AC, though interestingly Charlson/Deyo comorbidity score did not appear to alter its use. However, it is likely that considerable co-linearity between higher comorbidity scores and likelihood of postoperative complications, both of which were included in our statistical model, may explain the lack of significance. Socioeconomic factors including race, income and education level do not appear to have an independent effect on the use of $\mathrm{AC}$, however longer distance to the treatment facility lowered the odds of receiving AC. While this could be related to geographic and center-level variation, it more likely represents a logistical burden for patients who are required to travel longer distances to receive their care.

While the primary purpose of this study was to examine adjuvant chemotherapy use, we also examined the addition of radiation therapy to AC. In an exploratory Cox proportional hazards model, the addition of radiation therapy to the model resulted in neither adjuvant radiation nor chemotherapy having an independent association with long-term survival. As this was likely due to significant co-linearity between the two variables ( $71 \%$ of the AC patients also received radiation therapy), we then conducted a comparison of survival among patients treated with only AC versus combined adjuvant chemoradiation, and found no significant difference between the two groups. These results suggest that the substantial survival advantage associated with adjuvant therapy is due to chemotherapy. Although radiation may confer some benefits in terms of local control as evidenced by the studies that investigated adjuvant therapy for gastric cancer, these benefits may be offset by complications related to treatment of the conduit after esophageal cancer resection. Our results suggest that among patients with node-positive disease following esophagectomy, radiation does not effect overall survival. Given these findings, more study is needed regarding the impact of postoperative radiation therapy on patients recently treated with esophagectomy.

The NCDB offers significant advantages over existing studies due to its large size and population-based nature. Regardless, the database does have inherent limitations. First, this was a retrospective study, and as such is subject to intrinsic selection bias. While our patient population was defined by fairly strict criteria regarding indications for $\mathrm{AC}$ (R0 resection and node-positive disease, in the absence of induction treatment), it is possible that some patients were not treated with AC due to comorbidities or the belief that they would not safely tolerate chemotherapy following the expected insult of an esophagectomy. Second, the NCDB does not provide specific complication data such as anastomotic leak, pneumonia, or sepsis, and therefore our definition of postoperative complications is based on measured indicators. While we felt that an unplanned readmission or length of stay $>20$ days was clearly related to a non-routine postoperative course, it is possible that the actual complication rate was much higher, and we were simply unable to detect less severe 
occurrences based on the criteria used. Lastly, cancer-specific survival and recurrence data are not available in the NCDB, both of which may be particularly important in our analyses of patients experiencing postoperative complications.

In conclusion, adjuvant chemotherapy is associated with a substantial survival advantage for patients with positive nodal disease following esophagectomy. Esophagectomy remains a highly morbid procedure with considerable risk of postoperative complications. Patients who can be rescued to proceed to AC despite complications fare as well as patients treated with AC but who had an uncomplicated course. In light of the meaningful survival benefit associated with AC despite complications, great effort should be made to ensure that patients who experience a complicated course following esophagectomy are given strong consideration for treatment with $\mathrm{AC}$ if at all possible.

\section{Acknowledgments}

The NCDB is a joint project of the Commission on Cancer of the American College of Surgeons and the American Cancer Society. The data used in the study are derived from a de-identified NCDB file. The American College of Surgeons and the Commission on Cancer have not verified and are not responsible for the analytic or statistical methodology employed, or the conclusions drawn from these data by the investigators.

Sources of support and disclosures: This work was supported by the NIH funded Cardiothoracic Surgery Trials Network (M.G.H and M.F.B). One of the authors (T.A.D.) serves as a consultant for Scanlan International, Inc.

\section{References}

1. Howlader, N.; Noone, AM.; Krapcho, M., et al. SEER Cancer Statistics Review, 1975-2008. National Cancer Institute; Bethesda, MD: 2011. http://seer.cancer.gov/csr/1975_2008/, based on November 2010 SEER data submission, posted to the SEER web site, 2011

2. Enzinger PC, Mayer RJ. Esophageal cancer. N Engl J Med. 2003; 349:2241-52. [PubMed: 14657432]

3. Pennathur A, Luketich JD. Resection for esophageal cancer: strategies for optimal management. Ann Thorac Surg. 2008; 85:S751-6. [PubMed: 18222210]

4. Siegel R, Naishadham D, Jemal A. Cancer statistics, 2012. CA Cancer J Clin. 2012; 62:10-29. [PubMed: 22237781]

5. Dubecz A, Gall I, Solymosi N, et al. Temporal trends in long-term survival and cure rates in esophageal cancer: a SEER database analysis. J Thorac Oncol. 2012; 7:443-7. [PubMed: 22173700]

6. Horner, M.; Ries, L.; Krapcho, M., et al. SEER Cancer Statistics Review, 1975-2006. National Cancer Institute; Bethesda, MD: 2009. http://seer.cancer.gov/csr/1975_2006/, based on November 2008 SEER data submission, posted to the SEER web site

7. Rice TW, Rusch VW, Ishwaran H, et al. Cancer of the esophagus and esophagogastric junction: data-driven staging for the seventh edition of the American Joint Committee on Cancer/ International Union Against Cancer Cancer Staging Manuals. Cancer. 2010; 116:3763-73. [PubMed: 20564099]

8. Smith GL, Smith BD, Buchholz TA, et al. Patterns of care and locoregional treatment outcomes in older esophageal cancer patients: The SEER-Medicare Cohort. Int J Radiat Oncol Biol Phys. 2009; 74:482-9. [PubMed: 19289262]

9. Worni M, Castleberry AW, Gloor B, et al. Trends and outcomes in the use of surgery and radiation for the treatment of locally advanced esophageal cancer: a propensity score adjusted analysis of the surveillance, epidemiology, and end results registry from 1998 to 2008. Dis Esophagus. 2013 Aug 13. Epub ahead of print.

10. Burmeister BH, Smithers BM, Gebski V, et al. Surgery alone versus chemoradiotherapy followed by surgery for resectable cancer of the oesophagus: a randomised controlled phase III trial. Lancet Oncol. 2005; 6:659-68. [PubMed: 16129366] 
11. Tepper J, Krasna MJ, Niedzwiecki D, et al. Phase III trial of trimodality therapy with cisplatin, fluorouracil, radiotherapy, and surgery compared with surgery alone for esophageal cancer: CALGB 9781. J Clin Oncol. 2008; 26:1086-92. [PubMed: 18309943]

12. Sjoquist KM, Burmeister BH, Smithers BM, et al. Survival after neoadjuvant chemotherapy or chemoradiotherapy for resectable oesophageal carcinoma: an updated meta-analysis. Lancet Oncol. 2011; 12:681-92. [PubMed: 21684205]

13. Schwer AL, Ballonoff A, McCammon R, et al. Survival effect of neoadjuvant radiotherapy before esophagectomy for patients with esophageal cancer: a surveillance, epidemiology, and end-results study. Int J Radiat Oncol Biol Phys. 2009; 73:449-55. [PubMed: 18538500]

14. Solomon N, Zhuge Y, Cheung M, et al. The roles of neoadjuvant radiotherapy and lymphadenectomy in the treatment of esophageal adenocarcinoma. Ann Surg Oncol. 2010; 17:791-803. [PubMed: 19953332]

15. van Hagen P, Hulshof MC, van Lanschot JJ, et al. Preoperative chemoradiotherapy for esophageal or junctional cancer. N Engl J Med. 2012; 366:2074-2084. [PubMed: 22646630]

16. Ajani JA, Barthel JS, Bentrem DJ, et al. Esophageal and esophagogastric junction cancers. J Natl Compr Canc Netw. 2011; 9:830-87. [PubMed: 21900218]

17. Macdonald JS, Smalley SR, Benedetti J, Hundahl SA, Estes NC, Stemmermann GN, Haller DG, Ajani JA, Gunderson LL, Jessup JM, Martenson JA. Chemoradiotherapy after surgery compared with surgery alone for adenocarcinoma of the stomach or gastroesophageal junction. N Engl J Med. 2001 Sep 6; 345(10):725-30. [PubMed: 11547741]

18. Smalley SR, Benedetti JK, Haller DG, Hundahl SA, Estes NC, Ajani JA, et al. Updated analysis of SWOG-directed intergroup study 0116: a phase III trial of adjuvant radiochemotherapy versus observation after curative gastric cancer resection. J Clin Oncol. 201210.1200/jco.2011.36.7136

19. Lee J, Lim DH, Kim S, Park SH, Park JO, Park YS, et al. Phase III trial comparing capecitabine plus cisplatin versus capecitabine plus cisplatin with concurrent capecitabine radiotherapy in completely resected gastric cancer with D2 lymph node dissection: the ARTIST trial. J Clin Oncol. 2012; 30(3):268-73. [PubMed: 22184384]

20. Sakuramoto S, Sasako M, Yamaguchi T, Kinoshita T, Fujii M, Nashimoto A, et al. Adjuvant chemotherapy for gastric cancer with S-1, an oral fluoropyrimidine. N Engl J Med. 2007; 357(18): 1810-20. [PubMed: 17978289]

21. Sasako M, Sakuramoto S, Katai H, Kinoshita T, Furukawa H, Yamaguchi T, et al. Five-year outcomes of a randomized phase III trial comparing adjuvant chemotherapy with S-1 versus surgery alone in stage II or III gastric cancer. J Clin Oncol. 2011; 29(33):4387-93. [PubMed: 22010012]

22. Bang YJ, Kim YW, Yang HK, Chung HC, Park YK, Lee KH, et al. Adjuvant capecitabine and oxaliplatin for gastric cancer after D2 gastrectomy (CLASSIC): a phase 3 open-label, randomised controlled trial. Lancet. 2012; 379(9813):315-21. [PubMed: 22226517]

23. Noh SH, Park SR, Yang HK, Chung HC, Chung IJ, Lee KH, et al. Adjuvant capecitabine and oxaliplatin (XELOX) for gastric cancer after D2 gastrectomy: final results from the CLASSIC trial. Ann Oncol. 2013; 24(Suppl 4):iv14.

24. Atkins BZ, Shah AS, Hutcheson KA, et al. Reducing hospital morbidity and mortality following esophagectomy. Ann Thorac Surg. Oct; 2004 78(4):1170-1176. discussion 1170-1176. [PubMed: 15464465]

25. Bailey SH, Bull DA, Harpole DH, et al. Outcomes after esophagectomy: a ten-year prospective cohort. Ann Thorac Surg. Jan; 2003 75(1):217-222. [PubMed: 12537219]

26. Chang AC, Ji H, Birkmeyer NJ, Orringer MB, Birkmeyer JD. Outcomes after transhiatal and transthoracic esophagectomy for cancer. Ann Thorac Surg. Feb; 2008 85(2):424-429. [PubMed: 18222237]

27. Rentz J, Bull D, Harpole D, et al. Transthoracic versus transhiatal esophagectomy: a prospective study of 945 patients. J Thorac Cardiovasc Surg. May; 2003 125(5):1114-1120. [PubMed: 12771885]

28. Dimick JB, Wainess RM, Upchurch GR Jr, Iannettoni MD, Orringer MB. National trends in outcomes for esophageal resection. Ann Thorac Surg. Jan; 2005 79(1):212-216. discussion 217-218. [PubMed: 15620945] 
29. Ra J, Paulson EC, Kucharczuk J, et al. Postoperative mortality after esophagectomy for cancer: development of a preoperative risk prediction model. Ann SurgOncol. Jun; 2008 15(6):1577-1584.

30. Wright CD, Kucharczuk JC, O'Brien SM, Grab JD, Allen MS. Predictors of major morbidity and mortality after esophagectomy for esophageal cancer: a Society of Thoracic Surgeons General Thoracic Surgery Database risk adjustment model. J Thorac Cardiovasc Surg. Mar; 2009 137(3): 587-595. [PubMed: 19258071]

31. de Boer AG, van Lanschot JJ, van Sandick JW, et al. Quality of life after transhiatal compared with extended transthoracic resection for adenocarcinoma of the esophagus. J Clin Oncol. Oct 15; 2004 22(20):4202-4208. [PubMed: 15483031]

32. Moorcraft SY, Smyth EC, Cunningham D. Adjuvant or neoadjuvant therapy for operable esophagogastric cancer. Gastric Cancer. 2014 Epub 18 March 2014.

33. Crabtree TD, Kosinski AS, Puri V, et al. Evaluation of the reliability of clinical staging of T2 N0 esophageal cancer: a review of the Society of Thoracic Surgeons database. Ann Thorac Surg. 2013; 96:382-390. [PubMed: 23731608]

34. Crabtree TD, Yacoub WN, Puri V, et al. Endoscopic ultrasound for early stage esophageal adenocarcinoma: implications for staging and survival. Ann Thorac Surg. 2011; 91:1509-1515. discussion 1515-1506. [PubMed: 21435632]

35. DeWitt J, Kesler K, Brooks JA, et al. Endoscopic ultrasound for esophageal and gastroesophageal junction cancer: Impact of increased use of primary neoadjuvant therapy on preoperative locoregional staging accuracy. Dis Esoph. 2005; 18:21-27.

36. Kutup A, Link BC, Schurr PG, et al. Quality control of endoscopic ultrasound in preoperative staging of esophageal cancer. Endoscopy. 2007; 39:715-719. [PubMed: 17661247]

37. Pech O, Günter E, Dusemund F, Origer J, Lorenz D, Ell C. Accuracy of endoscopic ultrasound in preoperative staging of esophageal cancer: results from a referral center for early esophageal cancer. Endoscopy. 2010; 42:456-461. [PubMed: 20306385]

38. Stiles BM, Mirza F, Coppolino A, et al. Clinical T2-T3N0M0 esophageal cancer: the risk of node positive disease. Ann Thorac Surg. 2011; 92:491-496. [PubMed: 21704291] 


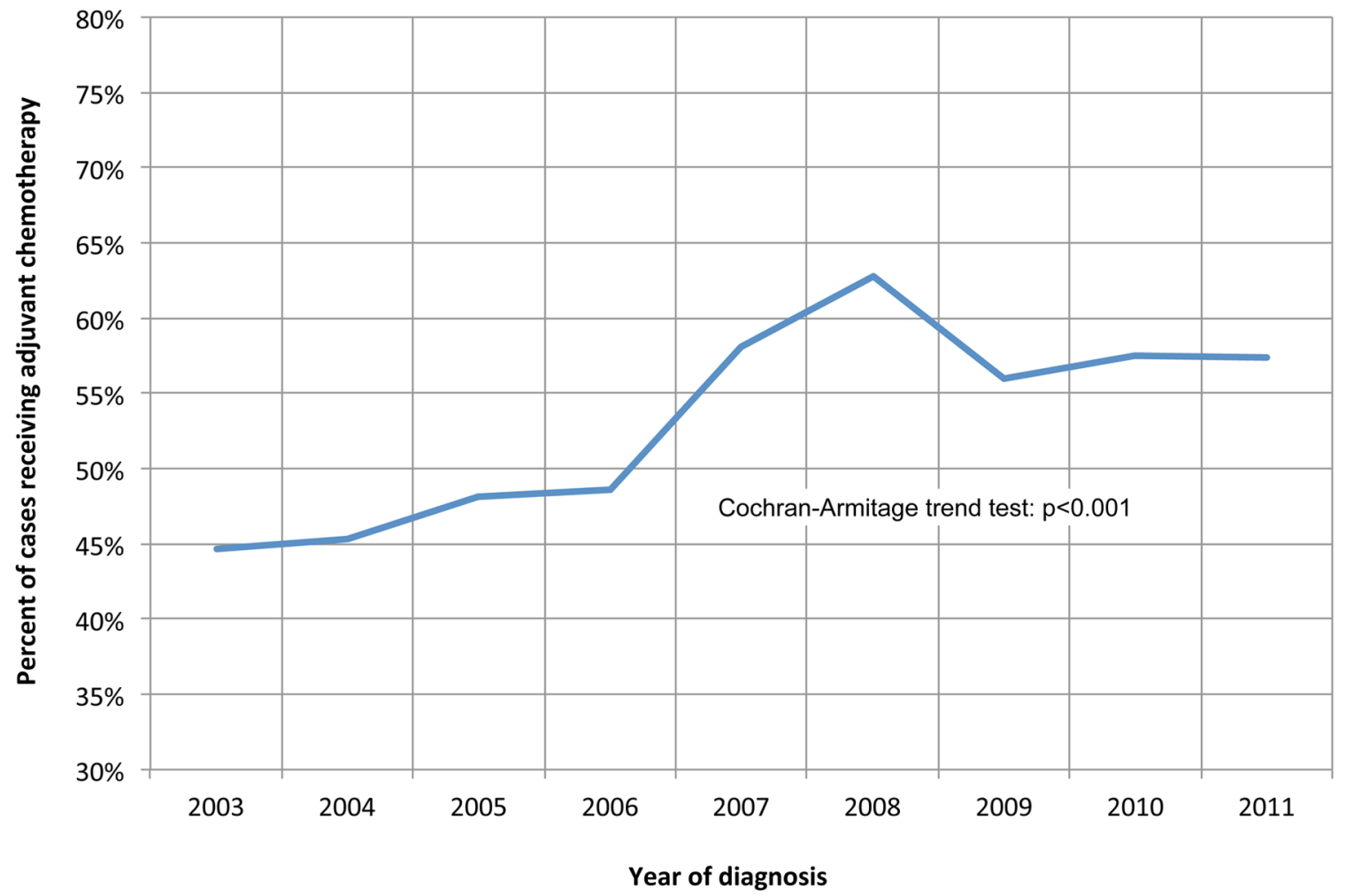

Figure 1. Trends in the use of adjuvant chemotherapy following margin-negative, node-positive esophagectomy 

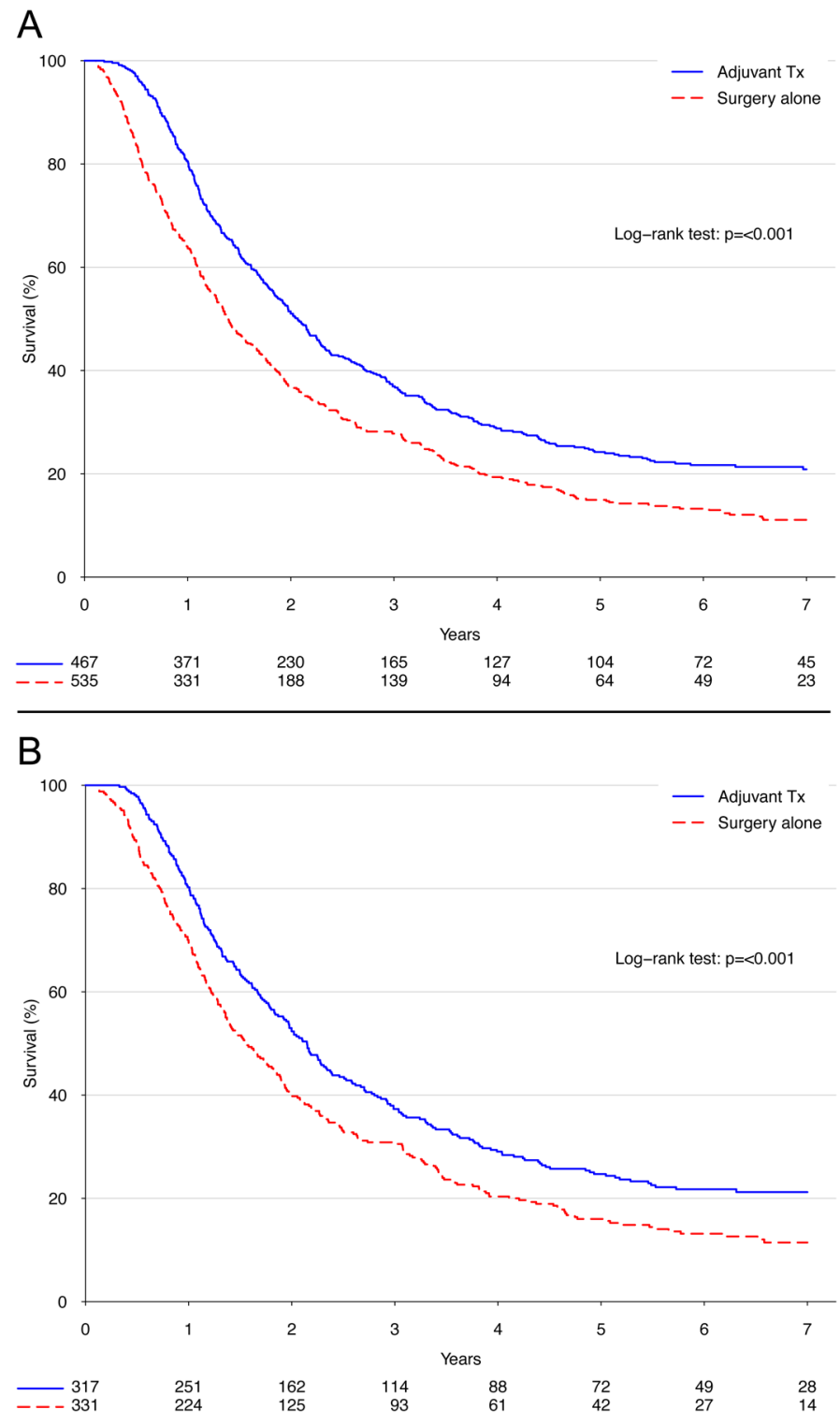

Figure 2.

Kaplan-Meier survival curves for patients (A) treated with versus without adjuvant chemotherapy; and (B) treated with versus without adjuvant chemotherapy and excluding patients experiencing a postoperative complication (defined as an unplanned readmission or length of stay $>20$ days). 

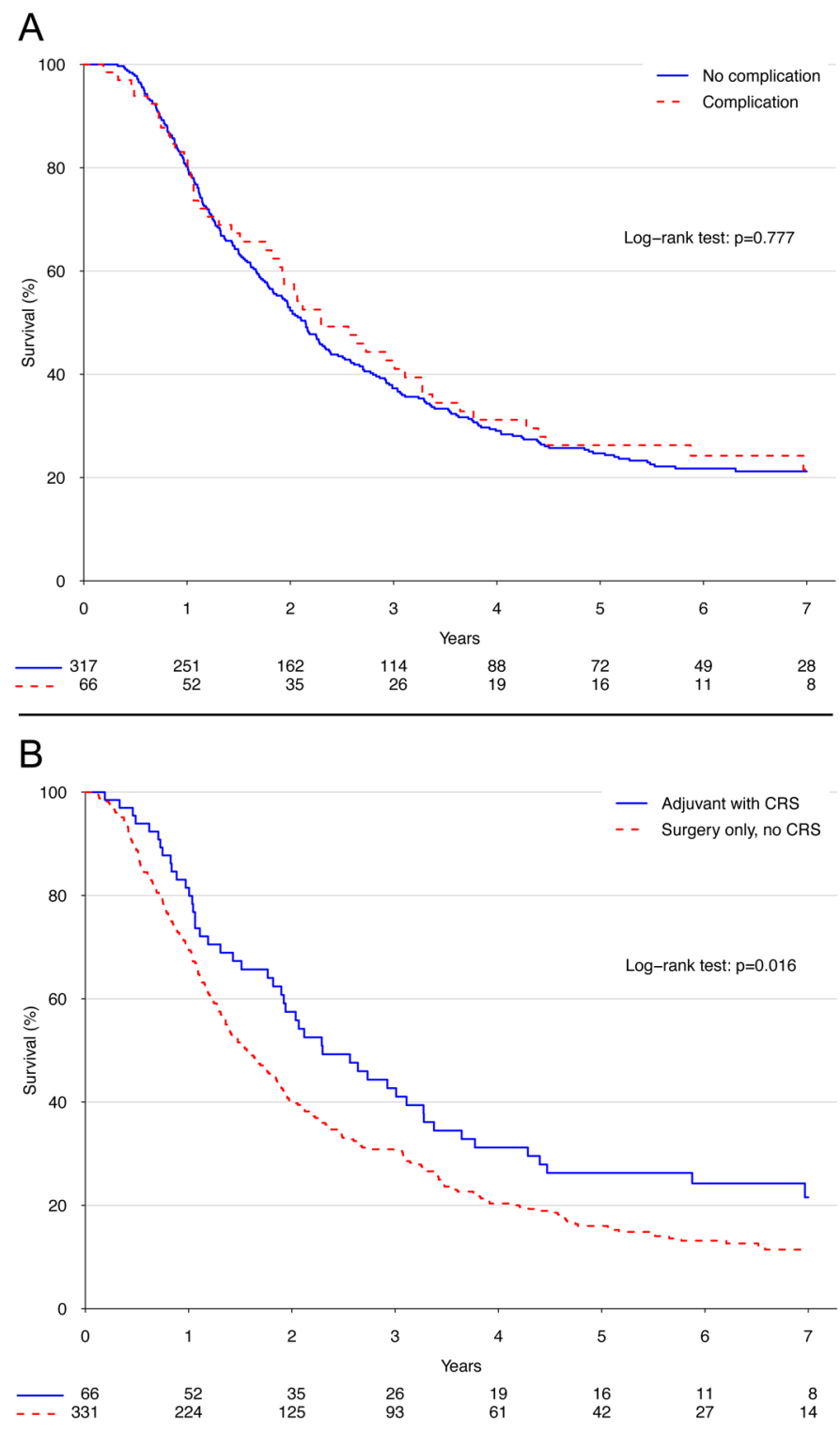

Figure 3.

Kaplan-Meier survival curves for patients who experienced a postoperative complication but were rescued to receive intended adjuvant chemotherapy compared to patients who (A) received adjuvant chemotherapy in the absence of complications; and (B) patients who did not experience complications or get adjuvant therapy. 
Table 1

Baseline characteristics between groups

\begin{tabular}{|c|c|c|c|c|}
\hline Variable & Total $(n=1,694)$ & No chemo $(n=820)$ & Adjuvant chemo $(n=874)$ & P-value \\
\hline \multicolumn{5}{|l|}{ Patient characteristics } \\
\hline Age, yrs (IQR) & $64(56,72)$ & $67(59,75)$ & $61(54,68)$ & $<0.001$ \\
\hline Female & $201(11.9 \%)$ & $106(12.9 \%)$ & $95(10.9 \%)$ & 0.217 \\
\hline Race & & & & 0.496 \\
\hline White & $1,631(97.2 \%)$ & $790(97.4 \%)$ & $841(97 \%)$ & \\
\hline Black & $25(1.5 \%)$ & $13(1.6 \%)$ & $12(1.4 \%)$ & \\
\hline Other & $22(1.3 \%)$ & $8(1 \%)$ & $14(1.6 \%)$ & \\
\hline Charlson Comorbidity Score & & & & $<0.001$ \\
\hline $\mathbf{0}$ & $1,166(68.8 \%)$ & $532(64.9 \%)$ & $634(72.5 \%)$ & \\
\hline 1 & $414(24.4 \%)$ & $211(25.7 \%)$ & $203(23.2 \%)$ & \\
\hline$\geq 2$ & $114(6.7 \%)$ & $77(9.4 \%)$ & $37(4.2 \%)$ & \\
\hline Education above median & $1,016(63.1 \%)$ & $492(63.5 \%)$ & $524(62.7 \%)$ & 0.777 \\
\hline Income above median & $1,100(68.3 \%)$ & $527(68 \%)$ & $573(68.5 \%)$ & 0.858 \\
\hline Insurance & & & & $<0.001$ \\
\hline Private & $811(48.7 \%)$ & $316(39 \%)$ & $495(58 \%)$ & \\
\hline Medicare & $747(44.9 \%)$ & $439(54.2 \%)$ & $308(36.1 \%)$ & \\
\hline Medicaid & $57(3.4 \%)$ & $30(3.7 \%)$ & $27(3.2 \%)$ & \\
\hline Government & $18(1.1 \%)$ & $8(1 \%)$ & $10(1.2 \%)$ & \\
\hline Uninsured & $31(1.9 \%)$ & $17(2.1 \%)$ & $14(1.6 \%)$ & \\
\hline \multicolumn{5}{|l|}{ Tumor characteristics } \\
\hline Tumor size & & & & 0.48 \\
\hline$<1 \mathrm{~cm}$ & $39(2.5 \%)$ & $19(2.5 \%)$ & $20(2.5 \%)$ & \\
\hline $1-1.9 \mathrm{~cm}$ & $124(8 \%)$ & $65(8.6 \%)$ & $59(7.4 \%)$ & \\
\hline $2-4.9 \mathrm{~cm}$ & $889(57.3 \%)$ & $440(58.4 \%)$ & $449(56.3 \%)$ & \\
\hline$>4.9 \mathrm{~cm}$ & $499(32.2 \%)$ & $229(30.4 \%)$ & $270(33.8 \%)$ & \\
\hline Pathologic T-stage & & & & 0.872 \\
\hline T1 & $307(18.3 \%)$ & $154(18.9 \%)$ & $153(17.7 \%)$ & \\
\hline $\mathbf{T} 2$ & $322(19.2 \%)$ & $159(19.5 \%)$ & $163(18.8 \%)$ & \\
\hline T3 & $999(59.4 \%)$ & $477(58.5 \%)$ & $522(60.3 \%)$ & \\
\hline T4 & $53(3.2 \%)$ & $25(3.1 \%)$ & $28(3.2 \%)$ & \\
\hline \multicolumn{5}{|l|}{ Facility characteristics } \\
\hline Distance to cancer center (IQR) & $15.6(6,39.6)$ & $20.2(7.4,54.4)$ & $12.6(4.8,30.4)$ & 0.016 \\
\hline Treatment facility & & & & $<0.001$ \\
\hline Academic/Research Program & $793(47 \%)$ & $438(53.7 \%)$ & $355(40.8 \%)$ & \\
\hline Community Program & $893(53 \%)$ & $377(46.3 \%)$ & $516(59.2 \%)$ & \\
\hline Surgical endpoints & & & & \\
\hline
\end{tabular}




\begin{tabular}{lcccr}
\hline Variable & Total $(\mathbf{n}=\mathbf{1 , 6 9 4})$ & No chemo $(\mathbf{n}=\mathbf{8 2 0})$ & Adjuvant chemo $(\mathbf{n}=\mathbf{8 7 4})$ & P-value \\
\hline Nodes removed $(\mathbf{I Q R})$ & $13(8,19)$ & $13(8,19)$ & $13(9,20)$ & 0.334 \\
\hline Short-term outcomes & & & & \\
\hline 30-day readmission & $129(8 \%)$ & $74(9.4 \%)$ & $55(6.7 \%)$ & 0.064 \\
\hline Hospital LOS $(\mathbf{I Q R})$ & $11(8,16)$ & $13(9,21)$ & $10(8,14)$ & $<0.001$ \\
\hline Major complication & $390(26.5 \%)$ & $260(34.5 \%)$ & $130(18.1 \%)$ & $<0.001$ \\
\hline
\end{tabular}


Table 2

Independent predictors of adjuvant chemotherapy use following esophagectomy

\begin{tabular}{lcccc}
\hline Predictor & Odds ratio & Upper 95\% CI & Lower 95\% CI & p-value \\
\hline Age (per decade) & 0.58 & 0.49 & 0.70 & $<0.001$ \\
\hline Female sex & 0.74 & 0.41 & 1.33 & 0.308 \\
\hline Race (ref = White) & & & & \\
\hline Black & 5.77 & 0.64 & 52.24 & 0.119 \\
\hline Other & 3.08 & 0.18 & 51.50 & 0.434 \\
\hline Charlson score & 0.84 & 0.62 & 1.13 & 0.241 \\
\hline Education above median & 1.12 & 0.72 & 1.73 & 0.615 \\
\hline Income above median & 0.82 & 0.52 & 1.28 & 0.373 \\
\hline pT stage & 0.93 & 0.76 & 1.13 & 0.453 \\
\hline Distance traveled (per 100 miles) & 0.78 & 0.62 & 0.98 & 0.032 \\
\hline Complication related to surgery & 0.45 & 0.30 & 0.67 & $<0.001$ \\
\hline
\end{tabular}


Table 3

Adjusted predictors of long-term mortality, following Cox proportional hazards modeling

\begin{tabular}{lcccr}
\hline Risk factor/Predictor & Hazard ratio & Upper 95\% CI & Lower 95\% CI & p-value \\
\hline Adjuvant chemotherapy & 0.67 & 0.50 & 0.90 & 0.008 \\
\hline Age (per decade) & 1.11 & 0.97 & 1.27 & 0.13 \\
\hline Female sex & 0.91 & 0.56 & 1.50 & 0.72 \\
\hline Race (ref = White) & & & & \\
\hline Black & 2.15 & 0.78 & 5.94 & 0.138 \\
\hline Other & 8.07 & 1.08 & 60.12 & 0.042 \\
\hline Charlson score & 1.16 & 0.93 & 1.45 & 0.198 \\
\hline Pathologic T stage (per unit) & 1.57 & 1.31 & 1.87 & $<0.001$ \\
\hline Facility volume (per 10 cases) & 0.56 & 0.29 & 1.07 & 0.077 \\
\hline Complications related to surgery & 1.51 & 1.10 & 2.08 & 0.012 \\
\hline
\end{tabular}

